\title{
Polysaccharide Mushroom Extracts - Digging Into the Unknown
}

\author{
Jovana Vunduk
}

\begin{abstract}
Mushroom polysaccharide extracts are complex with many compounds that could block the signal which results in fluorescence that is covering some part or all the important data of the spectra. In other case the sample is emitting no signal at all. Mushroom polysaccharide extracts are shyly emerging in relation with Raman spectroscopy.
\end{abstract}

Polysaccharide mushroom extracts are complex systems obtained mainly by water extraction, and their prevailing compounds are polysaccharides, mainly glucans, which was confirmed by Raman studies of Moharram et al (2008). Depending on the mushroom species fruiting bodies could contain different proportions of different glucans.

Glucans are polymer compounds which consist of glucose units connected with $\alpha-(1,3), \alpha-(1,6), \beta-(1,4)$ and $\beta-(1,6)$ glycoside bonds (Synytsya and Novak,

How to cite this book chapter:

Vunduk, J. 2019. Polysaccharide Mushroom Extracts - Digging Into the Unknown. In: Vucelić Radović, B., Lazić, D. and Nikšić, M. (eds.) Application of Molecular Methods and Raman Microscopy/Spectroscopy in Agricultural Sciences and Food Technology, Pp. 167-170. London: Ubiquity Press. DOI: https://doi.org/10.5334/ bbj.l. License: CC-BY 4.0 
2013). These complex substances are known to be responsible for biological effect of medicinal mushrooms, mainly as immunomodulators (Kozarski et al., 2015). Chemical composition of mushroom extracts greatly depends on the type of extraction. Thus characterization of different kind of extracts could elucidate the effect of the applied extraction procedure.

Theoretically Raman microspectroscopy provides an effective tool for the observation of biological material such as mushroom extracts. This method is

- undestructive

- does not acquire coloring agents to make the material visible

- there is no special preparation procedure for the sample

- measurement lasts from several seconds to several minutes

Literature data evidence for the different wavelengths that have been used in aim to characterize polysaccharide extracts; the main two are 850 and 1064 $\mathrm{nm}$. Regions that belongs to polysaccharides are 1485-1464, 1363-1371, 1258-1267, 1118-1131, 1074-1084 and 1040-1048 $\mathrm{cm}^{-1}$ (Synytsya et al., 2009). Signals in the region between 750 and $950 \mathrm{~cm}^{-1}$ are from anomeric structures around glycoside bounds and they confirm $\alpha$ and $\beta$ configuration (MohačekGrošev et al., 2001). One could expect complex spectra of the polysaccharide samples due to a very large number of possible vibrations $(\mathrm{OH}, \mathrm{C}-\mathrm{H}, \mathrm{C}-\mathrm{C}, \mathrm{C}-\mathrm{C}-$ O, C-O, C-O-C, C-O-H) (Lamrood et al., 2014).

\section{Sample preparation}

Raman spectroscopy does not require a special preparation procedure. The sample could be measured directly - in bulk, or dissolved in water. This technique is not invasive. The amounts that are required for the measurement are several mg.

\section{Choosing the acquisition time}

Acquisition time is the time during which the sample is exposed to the laser beam. This parameter is not fixed, so it should be chosen according to the real sample. One should make several spectra with several acquisition times and choose the time which gains the best spectra.

\section{What is behind the expression „the good spectra“?}

A good spectrum is the one whose characteristic peaks are clearly separated, without regions that are covered with fluorescence, since the fluorescence covers the distinctive lines and does not enable characterization. In order to 
obtain the statistical significance of the data approximately 50 good spectra should be collected.

\section{Dead ends}

Theoretically Raman spectroscopy is the perfect tool for the mushroom extracts observation. In reality the situation is less promising. The mushroom samples are complex with many compounds that could block the signal which results in fluorescence that is covering some part or all the important data of the spectra. In other case the sample is emitting no signal at all. The reason for such behavior is complexity of the samples. Pure $\beta$-glucan is clearly visible with distinctive lines, but the samples contain not just this type of glucans, but the phenolic compounds and proteins, too. These later might result in no signal.

\section{Future perspective}

Mushroom extracts are shyly emerging in relation with Raman spectroscopy which means that this topic is at its start (hopefully) or an inadequate technique. More attempts should be made, with a complex purification of the samples.

\section{References}

Kozarski M, Klaus A, Jakovljević D, Todorović N, Vunduk J, Petrović P, Nikšić M, Vrvić MM, van Griensven L. Antioxidants of edible mushrooms. Molecules, 2015, 20, 19489-19525.

Lamrood PY, Ralegankar SD, Harpale VM. Application of Raman spectroscopy for chemical characterization and protein conformation of Agaricus bisporus (Lange) Imabch (Agaricomycetidae) spores. International Journal of Bioassays, 2014, 3, 3318-3323.

Mohaček-Grošev V, Božac R, Pupples GJ. Vibrational spectroscopic characterization of wild growing mushrooms and toadstools. Spectrochemica acta Part A, 2001, 57, 2815-2829.

Moharram HA, Salama MF, Hussein AA. Characterization of Oyster mushroom mycelia as a food supplement. Australian journal of Basic and Applied Sciences, 2008, 2, 632-642.

Synytsya a, Mičkova K, Synytsya A, Jablonsky I, Spevaček J, Erban V, Kovarikova E, Čopikova J. Glucans from fruit bodies of cultivated mushrooms Pleurotus ostreatus and Pleurotus eryngii: Structure and potential prebiotic activity. Carbohydrate polymers, 2009, 76, 648-556.

Synytsya A, Novak M. Structural diversity of fungal glucans. Carbohydrate polymers, 2013, 92, 792-809. 
